\title{
Kelayakan Transportasi Air Sungai Batanghari (Studi Kasus Angkutan Motor Ketek Di Desa Terusan Kabupaten Batanghari)
}

\author{
Rendy Al Akbar, Elvira Handayani*, Kiki Rizky Amalia \\ Program Studi Teknik Sipil Universitas Batanghari Jambi \\ *Correspondence email: Elvira.handayani2@yahoo.co.id
}

\begin{abstract}
Abstrak. Sungai Batanghari adalah sungai terpanjang di pulau Sumatera dengan panjang sungai kurang lebih 800 KM. Motor ketek adalah salah satu moda transportasi tradisional yang digunakan sebagai angkutan penyeberangan di Sungai Batanghari. Tujuan dari penelitian ini adalah untuk menganalisis kelayalan motor ketek melalui kepuasan dan penilaian para pengguna jasa transportasi motor ketek sebagai angkutan penyeberangan di sungai Batanghari Desa Terusan. Penelitian ini dilakukan di desa Terusan, Maro Sebo ilir Kabupaten Batanghari, Jambi. Penelitian dilakukan dengan cara meneyebarkan kuisioner kepada para pengguna/penumpang motor ketek. Pengamatan dilakukan selama 3 hari. . Data kuesioner dilakukan proses pengolahan data dengan bantuan komputer program Ms. Excel. Dari hasil pengumpulan data, secara keseluruhan kelayakan motor ketek sebagai angkutan transportasi di sungai Batanghari dinilai dari 15 pertanyaan antara lain yaitu: Desa Terusan-Pasar Terusan 8 Pertanyaan yang memiliki nilai Layak dengan persentase 53,33\%. 6 Pertanyaan yang memiliki nilai Cukup Layak dengan persentase $40 \%$ dan 1 Pertanyaan yang memiliki nilai Sangat Tidak Layak dengan persentase 6,67\% ,Pasar Terusan-Desa Terusan 11 Pertanyaan yang memiliki nilai Layak dengan persentase 73,33\%. 3 Pertanyaan yang memiliki nilai Cukup Layak dengan persentase $20 \%$ dan 1 Pertanyaan yang memiliki nilai Sangat Tidak Layak dengan persentase 6,67\%. Berdasarkan penilaian dan kepuasan motor ketek dari para pengguna jasa angkutan penyeberangan sungai Batanghari di desa Terusan, bahwa tingkat kelayakan motor ketek dari Desa Terusan - Pasar Terusan dan Pasar Terusan - Desa Terusan sebagai angkutan penyeberangan di nilai Layak untuk saat ini.
\end{abstract}

Kata Kunci : Kelayakan, Motor Ketek, Sungai Batanghari, Desa Terusan

\section{PENDAHULUAN}

Sungai Batanghari adalah sungai terpanjang di pulau Sumatera dengan panjang sungai kurang lebih 800 KM yang melalui beberapa daerah di Provinsi Sumatera Barat hingga Provinsi Jambi. Sungai Batanghari membelah Desa Terusan yang terletak di Kecamatan Muaro Sebo Ilir Kabupaten Batanghari menjadi dua bagian yang biasa dikenal sebagai Pasar Terusan dan Desa Terusan. Mayoritas masyarakat di Desa Terusan Pekerjaannya sebagai Pelajar/Mahasiswa, PNS, Pegawai Swasta, IRT dan Petani/Pedagang. Sehingga alternatif jalur terdekat yang dapat ditempuh oleh masyarakat adalah dengan menyebrangi sungai tersebut menggunakan transportasi air.

Salah satu moda transportasi air yang digunakan masyarakat di Desa Terusan yaitu motor ketek. Motor ketek merupakan jenis transportasi air tradisional mirip perahu namun telah menggunakan mesin dalam pengoperasiannya. Menurut observasi awal, peneliti melihat bahwa motor ketek yang ada belum memenuhi standar kelayakan untuk dijadikan sebagai moda trasnportasi umum karena belum mempertimbangkan muatan maksimal yang dapat ditanggung, sehingga mempengaruhi keselamtan penumpang. Permasalahan mengenai kondisi kelayakan transportasi sungai Batanghari perlu dikaji sebagai pertimbangan pembaharuan transportasi sungai serta standar kelayakan sarana transportasi motor ketek dan dermaga yang digunakan.

Pada penelitian difokuskan pada menganalisa kelayakan motor ketek sebagai angkutan transportasi di sungai Batanghari desa Terusan, dengan tujuan dapat tingkatkelayakan motor ketek melalui kepuasan dan penilaian para pengguna jasa transportasi motor ketek.

\section{LANDASAN TEORI \\ Transportasi}

Transportasi adalah kegiatan pemindahan penumpang dan barang dari satu tempat ketempat lain (Munawar,2005). Suatu transportasi dikatakan baik, apabila pertama waktu perjalanan cukup cepat, kedua tidak ada kemacetan, ketiga frekuensi pelayanan cukup aman dan nyaman.

\section{Peranan Transportasi}

Transportasi memegang peranan penting baik bagi perorangan, masyarakat luas, pertumbuhan perekonomian maupun sosial politik suatu negara. Nasution (2015) menyebutkan bahwa transportasi mampu menciptakan dan meningkatkan aksebilitas poteni-potensi sumber daya alam yang awalnya tidak bermanfaat menjadi terjangkau dan dapat diolah. Kemajuan transportasi juga membawa pada peningkatan mobilitas manusia dan membawa dampak pada kemajuan ekonomi. 


\section{Sistem Transportasi}

Sistem transportasi merupakan bentuk keterikatan dan keterkaitan antar penumpang, barang dan prasarana yang berinteraksi dalam rangka perpindahan orang atau barang yang tercakup dalam suatu tatanan, baik secara alami maupun buatan/rekayasa.

\section{Perencanaan Transportasi}

Perencanaan transportasi adalah suatu kegiatan perencanaan sistem transportasi yang sistematis yang bertujuan menyediakan layanan transportasi baik sarana maupun prasarananya disesuaikan dengan kebutuhan transportasi bagi masyarakat di suatu wilayah serta tujuan-tujuan kemasyarakatan yang lain. Perecanaan transportasi mempelajari faktor-faktor yang mempengaruhi kebutuhan orang atau barang. Faktor-faktor dapat berupa tata guna lahan, ekonomi, sosial budaya, teknologi transportasi dan faktor-faktor lain yang mungkin terkait.

\section{Angkutan Sungai}

Angkutan sungai merupakan angkutan yang telah berumur panjang karena telah tumbuh dan berkembang secara alami bahkan sebelum angkutan jalan (Munawar, 2005). Jalan bagi transportasi air ini selain bersifat alami (laut, sungai, danau), ada pula yang bersifat buatan manusia (kanal, banjir, danau buatan). Beberapa pengertian yang meyangkut Angkutan Sungai, Danau dan Penyeberangan (ASDP). Beberapa keunggulan dan kelemahan angkutan sungai yang dirangkum dari berbagai sumber adalah sebagai berikut:

a. Keunggulan:

1) Tidak perlu membuat/membangun jalan air karena sungai sebagai prasarana sudah tersedia secara alami dan pemeliharaan prasarana yang tidak terlalu memakan banyak biaya.

2) Dapat memberikan pelayanan dari pintu ke pintu untuk permukiman di pinggir sungai.

3) Mampu mencapai daerah pedalaman dengan dominasi perairan.

4) Kemampuan untuk mengangkut barang tanpa mempengaruhi pembebanan pada badan sungai (daya angkut bisa besar)

5) Ramah lingkungan dan tidak macet

b. Kelemahan:

1) Kecepatan umumnya lebihh rendah dibandingkan dengan moda lain.

2) Kenyamanan dan standar keselamatan realatif rendah

3) Ketersediaan saran pendukung masing kurang

\section{METODE}

\section{Jenis Data}

1. Data Primer, Data primer yang dibutuhkan dalam penelitian ini diperoleh dari penyebaran kuesioner.Kuesioner ini dikhususkan hanya pada pengguna jasa transportasi untuk menjawab tentang kelayakan transportasi motor ketek.

2. Data Sekunder,disini peneliti hanya dengan mengumpulkan data dan informasi dari buku, jurnal dan internet yang berkaitan dengan penelitian yang dilakukan.

\section{Teknik pengumpulan data}

Pengumpulan data dilakukan mengikuti prosedur dan tahapan penelitian sebagai berikut :

1. Pengumpulan Data Primer

Pengumpulan data primer merupakan pengumpulan data yang diperoleh dari hasil penelitian secara langsung kepada obyek penelitian. Pengumpulan data primer yang dilakukan yaitu :

a. Observasi Lapangan

Merupakan metode pengamatan langsung ke lokasi penelitian, untuk mengumpulkan data dan informasi yang berkaitan dengan penelitian.

b. Studi literatur

Studi literatur adalah mengumpulkan data dengan mempelajari dan menganalisa data literatur, dokumen dan peraturan serta referensi lainnya yang berkaitan dengan masalah yang diteliti.

c. Angket / Kuisioner

Angket / kuisioner adalah teknik pengumpulan data yang dilakukan dengan cara memberikan seperangkat pertanyaan kepada responden untuk di jawabnya.

d. Studi dokumentasi

Metode pengumpulan data ini ditunjukan untuk melengkapi data dalam analisis masalah di wilayah penelitian yang memerlukan informasi dari dokumen-dokumen yang ada hubungannya dengan objek yang menjadi studi. Untuk keperluan ini, kita harus melakukan studi dokumentasi.

2. Pengumpulan Data Sekunder 
Rendy Al Akbar, Elvira Handayani dan Kiki Rizky Amalia, Kelayakan Transportasi Air Sungai Batanghari (Studi Kasus Angkutan Motor Ketek Di Desa Terusan Kabupaten Batanghari)

Pengumpulan data sekunder merupakan pengumpulan data secara tidak langsung dari sumber/obyek. Data-data diperoleh dari tulisan seperti buku-buku teori, buku laporan, peraturan-peraturan, dan dokumen baik yang berasal dari instansi terkait maupun hasil kajian literatur.

\section{Pengisian Kuisioner}

Dalam penelitian ini menggunakan skala likert berdasarkan kuisioner. Skala likert merupakan suatu skala psikometrik yang umum digunakan dalam angket dan merupakan skala yang paling banyak digunakan dalam riset berupa survey.

\section{Pengolahan Data Penelitian}

Teknik pengolahan data dalam penelitian ini menggunakan perhitungan komputasi program Microsoft Excel karena program ini memiliki kemampuan analisa statistik cukup baik serta sistem manajemen data pada lingkungan grafis menggunakan menu kotak-kotak dialog sederhana, sehingga mudah dipahami cara pengoperasiannya.

\section{Diagram Alir Penelitian}

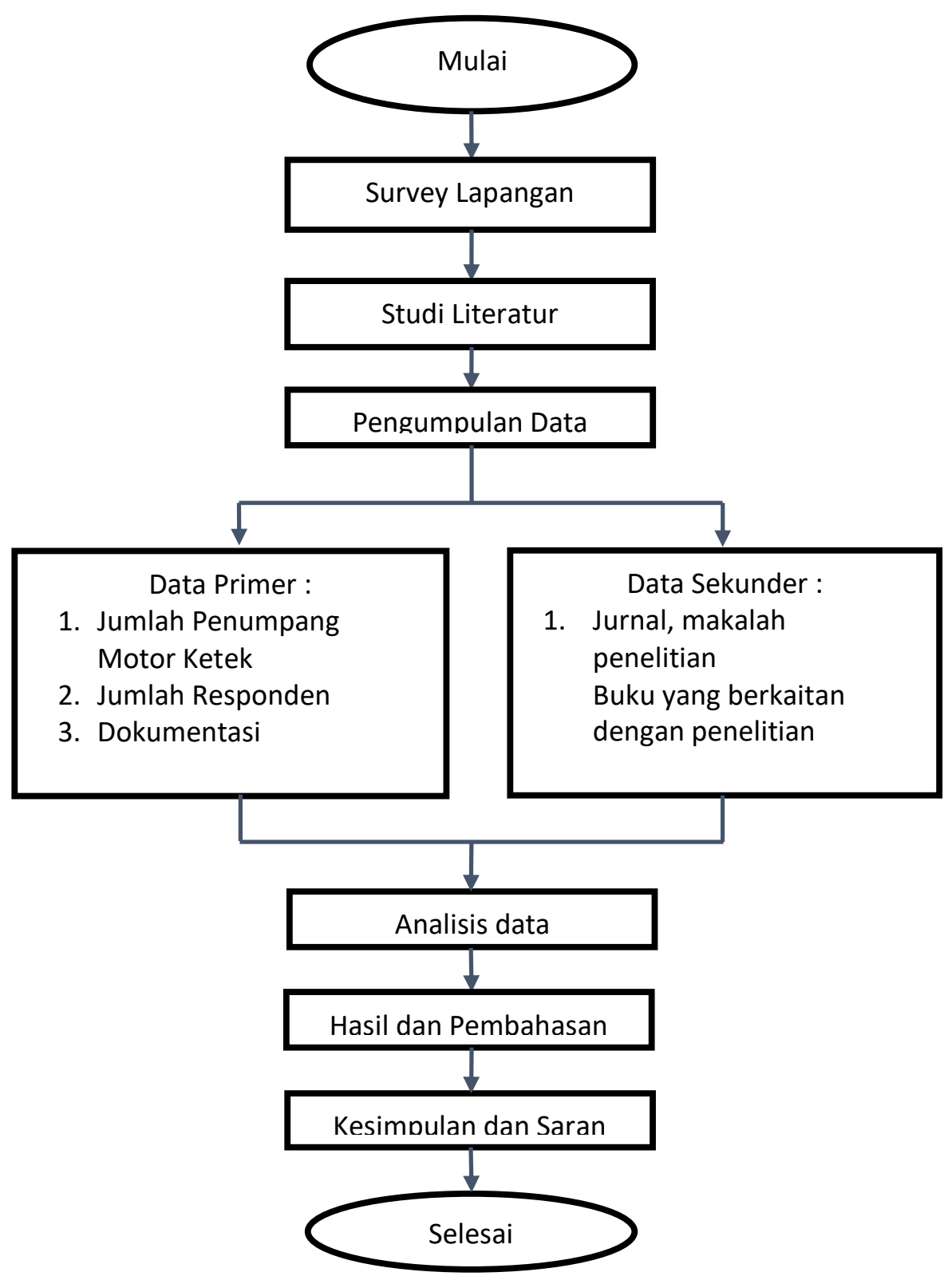

Sumber : Data Olahan, 2019

Gambar 1 Diagram Alur Penelitian 
Rendy Al Akbar, Elvira Handayani dan Kiki Rizky Amalia, Kelayakan Transportasi Air Sungai Batanghari (Studi Kasus Angkutan Motor Ketek Di Desa Terusan Kabupaten Batanghari)

\section{HASIL DAN PEMBAHASAN}

\section{Pengumpulan Data}

Pengambilan data dilakukan selama 3 hari yaitu pada tanggal 26,29 Februari 2020 dan 1 Maret 2020 di Desa Terusan kabupaten Batanghari. Pengambilan data dilakukan terhadap para responden yaitu para pengguna jasa angkutan motor ketek.

Berikut ini hasil survey lapangan jumlah penumpang yang menggunakan angkutan penyeberangan Sungai Batanghari di Desa Terusan Kabupaten Batanghari.

Tabel 1. Data Keseluruhan Jumlah Penumpang

\begin{tabular}{|c|c|c|c|c|c|c|c|c|}
\hline \multirow{2}{*}{$\begin{array}{l}\mathbf{N} \\
\mathbf{O}\end{array}$} & \multirow{2}{*}{ HARI } & \multicolumn{2}{|c|}{ 07:00-10:00 } & \multicolumn{2}{|c|}{ 10:00-14:00 } & \multicolumn{2}{|c|}{ 14:00-17:00 } & \multirow{2}{*}{$\begin{array}{l}\text { Jumlah } \\
\text { (Orang) }\end{array}$} \\
\hline & & Pergi & Pulang & Pergi & Pulang & Pergi & Pulang & \\
\hline 1 & RABU & 130 & 121 & 166 & 149 & 139 & 169 & 874 \\
\hline 2 & SABTU & 144 & 157 & 178 & 174 & 159 & 228 & 1040 \\
\hline 3 & MINGGU & 152 & 124 & 290 & 209 & 274 & 267 & 1316 \\
\hline & & & & nlah & & & & 3230 \\
\hline
\end{tabular}

Sumber : Survey lapangan, 2020

Keterangan :

Pergi : Desa Terusan ke Pasar Terusan

Pulang : Pasar Terusan ke Desa Terusan

Berdasarkan tabel di atas dapat diketahui bahwa jumlah keseluruhan penumpang pada survey selama 3 hari yaitu berjumlah 3230 penumpang.

Tabel 2. Data Jumlah Penumpang D.Terusan - P.Terusan

\begin{tabular}{ccc}
\hline No & HARI & $\begin{array}{c}\text { JUMLAH } \\
\text { (ORANG) }\end{array}$ \\
\hline 1 & RABU & 435 \\
2 & SABTU & 481 \\
3 & MINGGU & 716 \\
& Jumlah & 1632 \\
\hline
\end{tabular}

Sumber : Survey lapangan, 2020

Dimana Jumlah Responden minimal yaitu :

$n=\frac{1632}{1+\left(1632 \times 0,05^{2}\right)}=321$ Responden

Berdasarkan tabel di atas jumlah penumpang dari Desa Terusan ke Pasar Terusan yaitu berjumlah 1632 orang dimana jumlah Responden yang di ambil minimal 321 responden dan responden yang didapat berjumlah 322 responden

Tabel 3. Data Jumlah Penumpang P.Terusan - D.Terusan

\begin{tabular}{ccc}
\hline No & HARI & $\begin{array}{c}\text { JUMLAH } \\
\text { (ORANG) }\end{array}$ \\
\hline 1 & RABU & 439 \\
2 & SABTU & 559 \\
3 & MINGGU & 600 \\
& Jumlah & 1598 \\
\hline
\end{tabular}

Sumber : Survey lapangan, 2020

Dimana jumlah Responden minimal yaitu :

$n=\frac{1598}{1+\left(1598 \times 0,05^{2}\right)}=320$ Responden 
Rendy Al Akbar, Elvira Handayani dan Kiki Rizky Amalia, Kelayakan Transportasi Air Sungai Batanghari (Studi Kasus Angkutan Motor Ketek Di Desa Terusan Kabupaten Batanghari)

Berdasarkan tabel di atas jumlah penumpang dari Pasar Terusan ke Desa Terusan yaitu berjumlah 1598 orang dimana jumlah Responden yang di ambil minimal 320 responden dan responden yang didapat berjumlah 322 responden.

\section{Data Hasil Kuisioner}

Berikut ini menyajikan hasil Jumlah pilihan jawaban kuisioner responden:

Tabel 4. Jumlah Pilihan Jawaban Kuesioner Responden

\begin{tabular}{cccccccccccccccc}
\hline Skor & P1 & P2 & P3 & P4 & P5 & P6 & P7 & P8 & P9 & P10 & P11 & P12 & P13 & P14 & P15 \\
\hline 1 & 6 & 0 & 2 & 0 & 4 & 9 & 227 & 32 & 22 & 5 & 23 & 6 & 5 & 4 & 0 \\
2 & 8 & 0 & 16 & 22 & 34 & 58 & 98 & 74 & 126 & 60 & 90 & 56 & 96 & 18 & 8 \\
3 & 255 & 261 & 309 & 366 & 348 & 411 & 78 & 540 & 546 & 456 & 330 & 435 & 474 & 330 & 357 \\
4 & 724 & 772 & 704 & 628 & 680 & 516 & 48 & 256 & 196 & 528 & 540 & 560 & 388 & 656 & 552 \\
$\mathbf{5}$ & 230 & 210 & 165 & 160 & 75 & 90 & 40 & 45 & 30 & 15 & 45 & 15 & 70 & 175 & 305 \\
Jumlahskor & 1223 & 1243 & 1196 & 1176 & 1141 & 1084 & 491 & 947 & 920 & 1064 & 1028 & 1072 & 1033 & 1183 & 1222 \\
\hline
\end{tabular}

Sumber : Data Olahan (2020)

Berdasarkan tabel diatas tentang jumlah skor tiap-tiap kuesioner yaitu, P1: 1223, P2 : 1243, P3 : 1196, P4 : 1176, P5 : 1141, P6 :1084, P7 :491, P8 :947, P9 :920, P10 :1064, P11 :1028, P12 :1072, P13 :1033, P14 :1183, P15 :1222. Jadi Jumlah skor rata-rata berjumlah 1068,2 .

\section{Menghitung Jumlah skor}

Contoh perhitungan skor diambil dari atribut P1

Total Skor $=\mathrm{T} \times \mathrm{Pn}$

$=6 \times 1$

$=6$

Jadi :

Jumlah skor $=(1 \times 6)+(2 \times 4)+(3 \times 85)+(4 \times 181)+(5 \times 46)$

$=6+8+255+724+230$

$=1223$

Tabel 5. Jumlah Pilihan Jawaban Kuesioner Responden Desa Terusan - Pasar Terusan

Sumber : Data Olahan (2020)

\begin{tabular}{cccccccccccccccc}
\hline Skor & P1 & P2 & P3 & P4 & P5 & P6 & P7 & P8 & P9 & P10 & P11 & P12 & P13 & P14 & P15 \\
\hline 1 & 2 & 0 & 0 & 2 & 0 & 1 & 185 & 25 & 23 & 3 & 14 & 5 & 8 & 2 & 0 \\
2 & 18 & 0 & 14 & 12 & 14 & 72 & 138 & 98 & 112 & 66 & 68 & 58 & 80 & 8 & 12 \\
3 & 237 & 207 & 273 & 255 & 279 & 273 & 138 & 489 & 507 & 357 & 288 & 360 & 363 & 363 & 351 \\
4 & 652 & 732 & 600 & 700 & 648 & 600 & 72 & 264 & 232 & 552 & 620 & 576 & 508 & 500 & 400 \\
$\mathbf{5}$ & 345 & 350 & 370 & 270 & 300 & 220 & 20 & 95 & 80 & 145 & 115 & 120 & 130 & 350 & 495 \\
Jumlahskor & 1254 & 1289 & 1257 & 1239 & 1241 & 1166 & 553 & 971 & 954 & 1123 & 1105 & 1119 & 1089 & 1223 & 1258 \\
\hline
\end{tabular}

Berdasarkan tabel diatas tentang jumlah skor tiap-tiap kuesioner yaitu, P1: 1254, P2 : 1289, P3 : 1257, P4 : 1239, P5 : 1241, P6 :1166, P7 :553, P8 :971, P9 :954, P10 :1123, P11 :1105, P12 :1119, P13 :1089, P14 :1223, P15 :1258. Jadi Jumlah skor rata-rata berjumlah 1122,73. 
Rendy Al Akbar, Elvira Handayani dan Kiki Rizky Amalia, Kelayakan Transportasi Air Sungai Batanghari (Studi Kasus Angkutan Motor Ketek Di Desa Terusan Kabupaten Batanghari)

Tabel 6. Rekapitulasi Analisa Data Jawaban Responden

\begin{tabular}{|c|c|c|c|c|c|}
\hline \multirow{2}{*}{ No } & \multirow{2}{*}{\multicolumn{2}{|c|}{ Pertanyaan }} & \multirow{2}{*}{ Jawaban } & \multicolumn{2}{|c|}{ Persentase $(\%)$} \\
\hline & & & & DT - PT & PT - DT \\
\hline \multirow{18}{*}{1} & \multirow{18}{*}{ Aksesibilitas } & \multirow{5}{*}{$\begin{array}{l}\text { Kemudahan mencapai } \\
\text { lokasi penyeberangan }\end{array}$} & Sangat tidak layak & $1,9 \%$ & $0,6 \%$ \\
\hline & & & Tidak layak & $1,2 \%$ & $2,8 \%$ \\
\hline & & & Cukup layak & $26,4 \%$ & $24,5 \%$ \\
\hline & & & Layak & $56,2 \%$ & $50,6 \%$ \\
\hline & & & Sangat layak & $14,3 \%$ & $21,4 \%$ \\
\hline & & \multicolumn{2}{|c|}{ Jumlah } & $100 \%$ & $100 \%$ \\
\hline & & \multirow{5}{*}{ Waktu Tempuh } & Sangat tidak layak & 0 & 0 \\
\hline & & & Tidak layak & 0 & 0 \\
\hline & & & Cukup layak & $27,02 \%$ & $21,43 \%$ \\
\hline & & & Layak & $59,94 \%$ & $56,83 \%$ \\
\hline & & & Sangat layak & $13,04 \%$ & $21,74 \%$ \\
\hline & & \multicolumn{2}{|c|}{ Jumlah } & $100 \%$ & $100 \%$ \\
\hline & & \multirow{5}{*}{$\begin{array}{c}\text { Kapasitas } \\
\text { Penyeberangan }\end{array}$} & Sangat tidak layak & $0,6 \%$ & $0,0 \%$ \\
\hline & & & Tidak layak & $2,5 \%$ & $2,2 \%$ \\
\hline & & & Cukup layak & $32,0 \%$ & $28,3 \%$ \\
\hline & & & Layak & $54,7 \%$ & $46,6 \%$ \\
\hline & & & Sangat layak & $10,2 \%$ & $23,0 \%$ \\
\hline & & \multicolumn{2}{|c|}{ Jumlah } & $100 \%$ & $100 \%$ \\
\hline \multirow{6}{*}{2} & \multirow{6}{*}{ Ketersedian } & \multirow{5}{*}{$\begin{array}{c}\text { Kesiapan Motor ketek } \\
\text { untuk Dioperasikan }\end{array}$} & Sangat tidak layak & $0,0 \%$ & $0,6 \%$ \\
\hline & & & Tidak layak & $3,4 \%$ & $1,9 \%$ \\
\hline & & & Cukup layak & $37,9 \%$ & $26,4 \%$ \\
\hline & & & Layak & $48,8 \%$ & $54,3 \%$ \\
\hline & & & Sangat layak & $9,9 \%$ & $16,8 \%$ \\
\hline & & \multicolumn{2}{|c|}{ Jumlah } & $100 \%$ & $100 \%$ \\
\hline \multirow{6}{*}{3} & \multirow{6}{*}{ Keterjangkauan } & & Sangat tidak layak & $1,2 \%$ & $0,0 \%$ \\
\hline & & Riave Torif Angkutan & Tidak layak & $5,3 \%$ & $2,2 \%$ \\
\hline & & Dlaya larll Angkulan & Cukup layak & $36,0 \%$ & $28,9 \%$ \\
\hline & & & Layak & $52,8 \%$ & $50,3 \%$ \\
\hline & & & Sangat layak & $4,7 \%$ & $18,6 \%$ \\
\hline & & Jum & & $100 \%$ & $100 \%$ \\
\hline & & & Sangat tidak layak & $2,8 \%$ & $0,3 \%$ \\
\hline & & Kesesuaian Jumlah & Tidak layak & $9,0 \%$ & $11,2 \%$ \\
\hline 4 & Ketenatan & Kebutuhan & Cukup layak & $42,5 \%$ & $28,3 \%$ \\
\hline 4 & Ketepatan & Penumpang & Layak & $40,1 \%$ & $46,6 \%$ \\
\hline & & & Sangat layak & $5,6 \%$ & $13,7 \%$ \\
\hline & & Jum & & $100 \%$ & $100 \%$ \\
\hline & & & Sangat tidak layak & $70,5 \%$ & $57,5 \%$ \\
\hline & & & Tidak layak & $15,2 \%$ & $21,4 \%$ \\
\hline & & Pelampung & Cukup layak & $8,1 \%$ & $14,3 \%$ \\
\hline & & & Layak & $3,7 \%$ & $5,6 \%$ \\
\hline & & & Sangat layak & $2,5 \%$ & $1,2 \%$ \\
\hline & & Jum & & $100 \%$ & $100 \%$ \\
\hline & & & Sangat tidak layak & $9,9 \%$ & $7,8 \%$ \\
\hline & & Penutun Aton Motor & Tidak layak & $11,5 \%$ & $15,2 \%$ \\
\hline 5 & Keselamatan dan & Penutup Alap notor & Cukup layak & $55,9 \%$ & $50,6 \%$ \\
\hline $\mathrm{J}$ & Keamanan & & Layak & $19,9 \%$ & $20,5 \%$ \\
\hline & & & Sangat layak & $2,8 \%$ & $5,9 \%$ \\
\hline & & Jum & & $100 \%$ & $100 \%$ \\
\hline & & & Sangat tidak layak & $6,8 \%$ & $7,1 \%$ \\
\hline & & & Tidak layak & $19,6 \%$ & $17,4 \%$ \\
\hline & & Pegangan rangan & Cukup layak & $56,5 \%$ & $52,5 \%$ \\
\hline & & & Layak & $15,2 \%$ & $18,0 \%$ \\
\hline & & & Sangat layak & $1,9 \%$ & $5,0 \%$ \\
\hline & & Jum & & $100 \%$ & $100 \%$ \\
\hline
\end{tabular}


Rendy Al Akbar, Elvira Handayani dan Kiki Rizky Amalia, Kelayakan Transportasi Air Sungai Batanghari (Studi Kasus Angkutan Motor Ketek Di Desa Terusan Kabupaten Batanghari)

\begin{tabular}{|c|c|c|c|c|c|}
\hline \multirow{2}{*}{ No } & \multirow{2}{*}{\multicolumn{2}{|c|}{ Pertanyaan }} & \multirow{2}{*}{ Jawaban } & \multicolumn{2}{|c|}{ Persentase (\%) } \\
\hline & & & & DT - PT & PT - DT \\
\hline \multirow{24}{*}{6} & \multirow{24}{*}{ Kelayakan } & \multirow{5}{*}{ Ukuran Motor Ketek } & Sangat tidak layak & $1,6 \%$ & $0,9 \%$ \\
\hline & & & Tidak layak & $9,3 \%$ & $10,2 \%$ \\
\hline & & & Cukup layak & $47,2 \%$ & $37,0 \%$ \\
\hline & & & Layak & $41,0 \%$ & $42,9 \%$ \\
\hline & & & Sangat layak & $0,9 \%$ & $9,0 \%$ \\
\hline & & \multirow[t]{2}{*}{ Jumlah } & & $100 \%$ & $100 \%$ \\
\hline & & & Sangat tidak layak & $7,1 \%$ & $4,3 \%$ \\
\hline & & \multirow{4}{*}{$\begin{array}{l}\text { Tampilan Motor } \\
\text { Ketek }\end{array}$} & Tidak layak & $14,0 \%$ & $10,6 \%$ \\
\hline & & & Cukup layak & $34,2 \%$ & $29,8 \%$ \\
\hline & & & Layak & $41,9 \%$ & $48,1 \%$ \\
\hline & & & Sangat layak & $2,8 \%$ & $7,1 \%$ \\
\hline & & \multicolumn{2}{|c|}{ Jumlah } & $100 \%$ & $100 \%$ \\
\hline & & \multirow{5}{*}{ Lebar Motor Ketek } & Sangat tidak layak & $1,9 \%$ & $1,6 \%$ \\
\hline & & & Tidak layak & $8,7 \%$ & $9,0 \%$ \\
\hline & & & Cukup layak & $45,0 \%$ & $37,3 \%$ \\
\hline & & & Layak & $43,5 \%$ & $44,7 \%$ \\
\hline & & & Sangat layak & $0,9 \%$ & $7,5 \%$ \\
\hline & & \multicolumn{2}{|c|}{ Jumlah } & $100 \%$ & $100 \%$ \\
\hline & & \multirow{5}{*}{$\begin{array}{l}\text { Tempat Duduk } \\
\text { Penumpang }\end{array}$} & Sangat tidak layak & $1,6 \%$ & $2,5 \%$ \\
\hline & & & Tidak layak & $14,9 \%$ & $12,4 \%$ \\
\hline & & & Cukup layak & $49,1 \%$ & $37,6 \%$ \\
\hline & & & Layak & $30,1 \%$ & $39,4 \%$ \\
\hline & & & Sangat layak & $4,3 \%$ & $8,1 \%$ \\
\hline & & \multirow{6}{*}{$\begin{array}{l}\text { Menciptakan Peluang } \\
\text { Ekonomi }\end{array}$} & & $100 \%$ & $100 \%$ \\
\hline \multirow{12}{*}{7} & \multirow{12}{*}{ Manfaat Ekonomi } & & Sangat tidak layak & $1,2 \%$ & $0,6 \%$ \\
\hline & & & Tidak layak & $2,8 \%$ & $1,2 \%$ \\
\hline & & & Cukup layak & $34,2 \%$ & $37,6 \%$ \\
\hline & & & Layak & $50,9 \%$ & $38,8 \%$ \\
\hline & & & Sangat layak & $10,9 \%$ & $21,7 \%$ \\
\hline & & \multicolumn{2}{|c|}{ Jumlah } & $100 \%$ & $100 \%$ \\
\hline & & \multirow{5}{*}{$\begin{array}{l}\text { Meningkatkan Akses } \\
\text { ke berbagai Tempat }\end{array}$} & Sangat tidak layak & $0,0 \%$ & $0,0 \%$ \\
\hline & & & Tidak layak & $1,2 \%$ & $1,9 \%$ \\
\hline & & & Cukup layak & $37,0 \%$ & $36,3 \%$ \\
\hline & & & Layak & $42,9 \%$ & $31,1 \%$ \\
\hline & & & Sangat layak & $18,9 \%$ & $30,7 \%$ \\
\hline & & \multicolumn{2}{|c|}{ Jumlah } & $100 \%$ & $100 \%$ \\
\hline
\end{tabular}

Sumber : Data Olahan (2020)

Keterangan :

DT : Desa Terusan

PT : Pasar Terusan

Dari tabel Rekapitulasi diatas dapat diketahui tingkat kelayakan motor ketek seperti Aksesibilitas, ketersedian, Keterjangkauan, Ketepatan, keselamatan dan Keamanan, Kelayakan, dan Manfaat Ekonomi. Dari Tingkat kelayakan tersbut, berdasarkan pengamatan penulis dan didukung oleh tanggapan responden dari kuesioner yang diajukan, Aksesibilitas berdasarkan hasil kemudahan mencapai Lokasi Penyeberangan layak dengan persentase DT-PT 56,2 \% , PT-DT 50,6\%, Waktu tempuh layak dengan persentase DT-PT 59,94\%, PT-DT 56,83\%, Kapasitas Penyeberangan layak dengan persentase DT-PT 54,7\%, PT-DT 46,6\%, Kesiapan Motor ketek untuk dioperasikan layak dengan persentase DT-PT 48,8\%, PT-DT 54,3\% .

Keterjangkauan berdasarkan Biaya tarif angkutan penyeberangan layak dengan persentase DT-PT 52,8\% , PTDT 50,3\%. Ketepatan berdarkan Kesesuaian jumlah kebutuhan penumpang Cukup layak dengan persentase DT-PT 42,5\% , Layak persentase PT-DT 46,6\%

Keselamatan dan Keamanan berdasarkan Pelampung Sangat Tidak Layak dengan persentase DT-PT 70,5\% , PT-DT 57,5\% Penutup Atap Motor Ketek Cukup layak dengan persentase DT-PT 55,9\%, PT-DT 50,6\% , Pegangan Tangan penumpang Cukup Layak dengan persentase DT-PT 56,5\%, PT-DT 52,5\% .

Kelayakan berdasarkan Ukuran Motor Ketek Cukup Layak dengan persentase DT-PT 47,2\%, Layak persentase PT-DT 42,9\%, Tampilan Motor Ketek Layak dengan persentase DT-PT 41,9\%, PT-DT 48,1\%, Lebar Motor Ketek Cukup Layak dengan Persentase DT-PT 45\%, Layak persentase PT-DT 44,7\%, Tempat Duduk Penumpang Cukup Layak dengan persentase DT-PT 49,1\%, Layak PT-DT 39,4\%. 
Manfaat Ekonomi berdasarakan Menciptakan peluang ekonomi layak dengan persentase DT-PT 50,9\% , PT-DT 38,8\% dan Meningkatkan Akses ke berbagai tempat Layak dengan persentase DT-PT 42,9\% , Cukup Layak persentase PT-DT 36,3\%

Dari 15 atribut pertanyaan antara lain, DT-PT 8 pertanyaan memiliki nilai layak dengan persentase $=(8 / 15) \times$ $100 \%=53,33 \%, 6$ pertanyaan memiliki nilai cukup layak dengan persentase $=(6 / 15) \times 100 \%=40 \%$ dan 1 pertanyaan memiliki nilai tidak layak dengan persentase $=(1 / 15) \times 100 \%=6,67 \%$. PT-DT 11 pertanyaan memiliki nilai layak dengan persentase $=(11 / 15) \times 100 \%=73,33 \%, 3$ pertanyaan memiliki nilai cukup layak dengan persentase $=(3 / 15) \times$ $100 \%=20 \%$ dan 1 pertanyaan memiliki nilai tidak layak dengan persentase $=(1 / 15) \times 100 \%=6,67 \%$. Hasil rekapitulasi ini berdasarkan pengamatan penulis dan di dukung tanggapan responden dari hasil kuisioner yang di ajukan.

\section{SIMPULAN}

Berdasarkan hasil analisis mengenai Tingkat Kelayakan Motor Ketek Sebagai Angkutan Transportasi Di Sungai Batanghari dari sisi pengguna, maka didapat kesimpulan yaitu :

1. Dari sisi pengguna, secara keseluruhan kelayakan motor ketek sebagai angkutan transportasi di sungai Batanghari dinilai dari 15 pertanyaan antara lain yaitu: Desa Terusan-Pasar Terusan 8 Pertanyaan yang memiliki nilai Layak dengan persentase 53,33\%. 6 Pertanyaan yang memiliki nilai Cukup Layak dengan persentase 40\% dan 1 Pertanyaan yang memiliki nilai Sangat Tidak Layak dengan persentase 6,67\%, Pasar Terusan-Desa Terusan 11 Pertanyaan yang memiliki nilai Layak dengan persentase 73,33\%. 3 Pertanyaan yang memiliki nilai Cukup Layak dengan persentase 20\% dan 1 Pertanyaan yang memiliki nilai Sangat Tidak Layak dengan persentase 6,67\%

2. Berdasarkan penilaian dan kepuasan motor ketek dari para pengguna jasa angkutan penyeberangan sungai Batanghari di desa Terusan ,bahwa tingkat kelayakan motor ketek dari Desa Terusan - Pasar Terusan dan Pasar Terusan - Desa Terusan sebagai angkutan penyeberangan di nilai Layak untuk saat ini.

\section{Saran}

Berdasarkan hasil analisa maka peneliti merekomendasikan beberapa hal sebagai saran dalam memperbaikin tingkat kelayakan angkutan penyeberangan sungai batanghari di wilayah penelitian ini, yakni sebagai berikut :

1. Bagi pemilik motor ketek kiranya lebih memperhatikan sistem keselamatan seperti pelampung dan kelayakan penumpang sehingga kedepannya tidak terjadi hal yang di inginkan seperti kecelakan tenggelamnya motor ketek.

2. Pemerintah daerah perlu menyusun standar teknis motor ketek sebagai angkutan penyeberangan di sungai Batanghari, sehingga motor metek yang beroperasi mempunyai standar teknis menurut pemerintah.

\section{DAFTAR PUSTAKA}

Bahar, Akbar, 2018, Analisa Kebutuhan Angkutan Penyeberangan Sungai jeneberang Di Desa Taeng Kabupaten Goa,Makassar: UIN Alauddin Makassar.

Hasan, Iqbal. 2006. Analisis Data Penelitian Dengan Statistik. Jakarta : Bumi Aksara.

Keputusan Menteri Perhubungan Nomor 73 Tahun 2004 tentang Penyelenggaraan Angkutan Sungai dan Danau.

Munawar, Ahamad 2005, Dasar-Dasar Teknik Transportasi, Graha Ilmu, Yogyakarta.

Nasution. M. N, 2015, Manajemen Transportasi, Edisi Keempat Ghalia Indonesia, Jakarta.

Peraturan Pemerintah Nomor 82 Tahun 1999 Tentang Angkutan di Perairan,

Sari, R,P. 2008. Pergeseran Pergerakan angkutan Di Sungai Martapura Kota Banjarmasin, Semarang(Tesis): Universitas Diponegoro.

Sastika, Anta, 2017, Analisa Tingkat Pelayanan Perahu Ketek Sebagai Angkutan Wisata Di Sungai Musi Kota Palembang, Lampung(Tesis): Universitas Lampung.

Undang-Undang Nomor 17 Tahun 2008 tentang Pelayaran.

Tamin, Ofyar. Z, 2000, Perencanaan dan Pemodelan Transportasi. Edisi Kedua Bandung: Penerbit ITB. 